University of Wollongong

Research Online

Faculty of Social Sciences - Papers (Archive) Faculty of Arts, Social Sciences \& Humanities

2017

\title{
Assemblage thinking as methodology: commitments and practices for critical policy research
}

Tom Baker

University of Auckland

Pauline M. McGuirk

University of Wollongong, pmcguirk@uow.edu.au

Follow this and additional works at: https://ro.uow.edu.au/sspapers

Part of the Education Commons, and the Social and Behavioral Sciences Commons

Research Online is the open access institutional repository for the University of Wollongong. For further information contact the UOW Library: research-pubs@uow.edu.au 


\title{
Assemblage thinking as methodology: commitments and practices for critical policy research
}

\author{
Abstract \\ Assemblage thinking as methodology: commitments and practices for critical policy research. Territory, \\ Politics, Governance. The concept of assemblage has captured the attention of critical social scientists, \\ including those interested in the study of policy. Despite ongoing debate around the implications of \\ assemblage thinking for questions of structure, agency, and contingency, there is widespread agreement \\ around its value as a methodological framework. There are now many accounts using assemblage- \\ inflected methodologies of various sorts as analytical tools for revealing, interpreting, and representing \\ the worlds of policy-making, though few are explicit about their methodological practice. In this paper, we \\ identify a suite of epistemological commitments associated with assemblage thinking, including an \\ emphasis on multiplicity, processuality, labour, and uncertainty, and then consider explicitly how such \\ commitments might be translated into methodological practices in policy research. Drawing on a \\ research project on the development and enactment of homelessness policy in Australia, we explore how \\ three methodological practices $i$ adopting an ethnographic sensibility, tracing sites and situations, and \\ revealing labours of assembling $i$ can be used to operationalize assemblage thinking in light of the \\ challenges of conducting critical policy research.

\section{Disciplines} \\ Education | Social and Behavioral Sciences

\section{Publication Details} \\ Baker, T. \& McGuirk, P. (2017). Assemblage thinking as methodology: commitments and practices for \\ critical policy research. Territory, Politics, Governance, 5 (4), 425-442.
}




\title{
Assemblage thinking as methodology:
}

\section{Commitments and practices for critical policy research}

\author{
Tom Baker \\ Private Bag 92019 \\ School of Environment \\ University of Auckland \\ Auckland 1142 \\ New Zealand \\ Pauline $\mathbf{M}^{\mathrm{c}}$ Guirk \\ University of Wollongong, Australia
}

Published in Territory, Politics, Governance

Volume 5, 2017 - Issue 4 Pages 425-442 


\begin{abstract}
The concept of assemblage has captured the attention of critical social scientists, including those interested in the study of policy. Despite ongoing debate around the implications of assemblage thinking for questions of structure, agency, and contingency, there is widespread agreement around its value as a methodological framework. There are now many accounts using assemblage inflected methodologies of various sorts as analytical tools for revealing, interpreting, and representing the worlds of policy-making, though few are explicit about their methodological practice. In this paper, we identify a suite of epistemological commitments associated with assemblage thinking, including an emphasis on multiplicity, processuality, labour, and uncertainty, and then consider explicitly how such commitments might be translated into methodological practices in policy research. Drawing on a research project on the development and enactment of homelessness policy in Australia, we explore how three methodological practices-adopting an ethnographic sensibility, tracing sites and situations, and revealing labours of assembling — can be used to operationalise assemblage thinking in light of the challenges of conducting critical policy research.
\end{abstract}

\title{
Keywords
}

Assemblage thinking; assemblage methodologies; critical policy studies, policy-making 


\section{Finding 'Common Ground' with assemblage methodologies}

In August 2009, an Australian newspaper headline announced the arrival of a 'Big Apple plan for Sydney homeless' (Bibby and Murray 2009: n.p.). Contrasted with shelters and other approaches that 'managed' homelessness, it involved implementing a model claimed to be capable of 'ending' homelessness. Upending the traditional 'treatment first' approach, this Housing First model would provide direct access to permanent housing coupled with intensive, ongoing, clientdirected support services. It would be aimed specifically at the chronically homeless, a sub-group defined by multiple disabling conditions and long-term experiences of homelessness. The 'Big Apple' part of the plan referred to a particular Housing First model associated with Common Ground, a New York City organisation famed for its grand refurbishments of formerly derelict Midtown Manhattan hotels. Offering "more than just a short-term bed", New South Wales (NSW) Premier Nathan Rees supported Common Ground's Housing First model, in part, on the basis of its being "successfully established in New York and other cities" (ibid.). International evaluation evidence lent support to Housing First as a proven 'solution' to chronic homelessness. As NSW Housing Minister David Borger stated, "[a]ll the research tells us that providing chronically homeless people with long-term housing and strong support services can help get them back on their feet and break the cycle of homelessness" (ibid.). Data from another type of research — administrative cost-studies_was important too in promoting the policy shift, drawing decision-makers' attention to the high-cost nature of chronic homelessness. Awareness of an unrealised fiscal dividend began to dovetail with evidence of program effectiveness. Humanitarian and fiscal-economic justifications were thus drawn together, helping to assemble a new approach to chronic homelessness in Sydney. 
Days before the announcement of the Sydney Common Ground project, its fortunes were significantly improved with the signing of joint federal-state agreements on homelessness services and social housing. Given direction and momentum by the newly-elected Federal Labor government, led by Kevin Rudd (2007-10, 2013), the agreements included substantial funding increases for homelessness services and social housing, and were explicitly informed by Rudd's own childhood experience of homelessness. The favourable alignment of federal and state government agendas was clearly important in configuring and enabling the Sydney Common Ground project, yet local material conditions also played a decisive role. With a tight local property market ensuring that dilapidated hotel buildings were in short supply, the Sydney project departed from Common Ground's inspirational refurbishments in New York by opting for a new, purpose-built facility. This was the first of many local adaptations required to stabilise and embed the model in the Sydney context.

Ultimately, Sydney was not the only Australian city with a Big Apple plan for its homeless. In the wake of visits by Common Ground's founder Rosanne Haggerty, two projects in the South Australian city of Adelaide were already under construction by the time of the Sydney project's announcement, and another was being planned for the regional city of Port Augusta. In 2008, plans for a Common Ground project in Melbourne were made public. By mid-2009, two further projects had been ear-marked for Hobart and one for Brisbane. Among politicians, public officials, service providers and advocates, something of a policy awakening was sweeping across Australia, spurred by the potent assemblage of compatible ideology, compelling evidence in multiple forms and media, captivating success stories, and temporarily favourable funding circumstances, amongst other things. Housing First ideas and projects appeared to be reshaping policy norms, knowledge, and practice at local, regional, and national scales, all while being deeply 
embedded in globalising spaces and circuits (for a wider discussion of Housing First, see Baker and Evans 2016).

With this brief account of Housing First policy-making in Australia, we aim to establish an empirical reference point for this paper's main concern: the methodological application of assemblage thinking $^{1}$ in critical policy studies. As later discussion will make clear, this account has been informed by epistemological commitments associated with assemblage thinking, and by certain methodological practices that were chosen and enacted to operationalise those commitments in the context of policy research. Indeed, assemblage thinking-in variously ontological, methodological, and descriptive guises (Brenner et al. 2011) - has proven attractive to a broad range of social scientists in recent years. Within the transdisciplinary field of critical policy studies, assemblage thinking has taken on a methodological inflection, used as a tool to generate insights into the ways in which political-economic structures and governing institutions are (re)composed and (re)stabilised in the context of various conditions, actors, projects, and materials (Prince 2010; Clarke et al. 2015). We see these insights as useful complements to those generated through extant approaches, which typically_and valuably in our view_-illuminate the salience of those structures and institutions. Although assemblage-inspired methodologies have proliferated in critical policy scholarship, so far, little has been written about the connection between the epistemological commitments of assemblage thinking and its methodological practices. In this paper, we seek to

\footnotetext{
1 The terms assemblage thinking and assemblage theory are used interchangeably in the research literature. For the purposes of this paper, assemblage thinking refers to a diverse set of research accounts that may or may not engage directly with formal theories of assemblage, such as those of Deleuze and Guattari, or De Landa (see Müller (2015) for an overview of assemblage theory). Accounts that practice versions of assemblage thinking tend to display a relational ontology and some level of adherence to the four epistemological commitments discussed later in this paper.
} 
clarify this connection, drawing on our experience of applying assemblage methodologies. We use the empirical example of Housing First policy-making as an illustrative case.

The paper is divided into three main sections. In the next section, we define the concept of assemblage and synthesise recent debates and disagreements over assemblage thinking. We recognise a broad consensus, involving both advocates and critics, on the usefulness of assemblage thinking as a methodological-analytical approach. Building from this position, we discuss four epistemological commitments associated, to date, with assemblage thinking and assemblage methodologies, which were inherent in the brief account of Australian Housing First policy-making rehearsed above. Following this, we discuss the necessary but not straight-forward task of operationalising those commitments for the critical study of policy. To do so, we advocate three specific methodological practices. To illustrate these practices, we reflect on our attempt to find 'Common Ground' and common ground with assemblage methodologies.

\section{Debates, disagreements and consensus}

Few terms have become so readily embedded in critical social science as assemblage. Tanya Li (2007: 266) usefully defines assemblage as a "gathering of heterogeneous elements consistently drawn together as an identifiable terrain of action and debate". These elements include arrangements of humans, materials, technologies, organisations, techniques, procedures, norms, and events, all of which have the capacity for agency within and beyond the assemblage. Crucially, assemblages consist of and create spatialities. An assemblage "claims a territory", according to Wise (2005: 77), and is realised through ongoing processes of deterritorialisation and reterritorialisation, such that assemblages are continually in the process of being made and remade. The topographic spatiality of territory is underwritten by topologic spatialities, defined 
not by physical proximity or nested hierarchy but by variously distanciated associations that produce relational proximities (Prince 2015). With its emphasis on active composition-fitting, connecting, combining, and aligning relations between heterogeneous elements within and across space-the popularity of assemblage results in large part from its understanding of the social as "materially heterogeneous, practice-based, emergent and processual" (McFarlane 2009: 561). Thus, assemblage thinking has been applied to fields as diverse as public participation (Grove and Pugh 2015), urban development practices (Mㄷirk and Dowling 2009), industrial production (Swanton 2013) and - of particular relevance to this paper-the production, mobilisation, and implementation of policy (McCann 2011).

High levels of interest in the concept of assemblage have encouraged high levels of scrutiny (see special sections in City, Volume 15, Issues 2, 3-4, 5 and 6). Ongoing debates have been animated by differing truth claims concerning the nature of structure and agency, contingency, differing knowledge politics and, in an overarching sense, the nature of 'properly critical' social inquiry. Those skeptical of assemblage thinking-or, more specifically, of its elevation to the level of ontology—question its apparent lack of normativity, its resistance to abstraction, and its aversion to pre-given social categories. Brenner et al. (2011) object to the 'mercurial nature' of assemblage ontologies, claiming that researchers have attributed the notion of assemblage with "some rather impressive explanatory capabilities, up to a point at which its definitional parameters become extremely vague" (229). On the other hand, those embracing the possibilities of assemblage are concerned that a lingering structuralism dissuades some critical scholars from fully incorporating contingency, materiality, and the distributed nature of agency into their conceptions of the sociomaterial world. In contrast to the often settled way that macro-institutional and structural contexts 
feature in critical research, McFarlane (2011b: 379) claims that assemblage thinking offers a way to see "[p]olitical economies and structures emerge as relational products assembled through multiple routes, actors, histories, contingencies, resources, socio-materialities and power relations". In short, for some, assemblage thinking is complementary to critical theories founded in political economy, providing complementary means to grasp the multiplicity, complexity, and contingency of contemporary processes (McFarlane 2011a, 2011b; Rankin 2011; O'Callaghan 2012); for others, its emphasis on composition, distributed agency and non-linear causality can leave it inadequate, or even ontologically incompatible (Tonkiss 2011; Brenner et al. 2011; Peck 2014).

Despite these divergent perspectives on what the concept of assemblage can and should do, there are areas of widespread agreement. Most notably, there is loose consensus around the value of assemblage thinking as a methodological framework. Anderson and McFarlane (2011: 126) contend that assemblage "suggests a certain ethos of engagement with the world, one that experiments with methodological and presentational practices in order to attend to a lively world of differences". Similarly, Roy (2012: 35) notes that "the analytics of assemblage has come to pose important methodological questions for the social sciences", stressing that it is important to "make a distinction between assemblage as an object in the world and assemblage as a methodology". As otherwise trenchant critics of assemblage thinking, Brenner et al. (2011) support a "primarily methodological application", which "retains the central concerns, concepts and analytical orientations of political economy within a methodologically expanded framework" (232). Thus, notwithstanding ongoing debates over assemblage thinking, most of the interlocutors have welcomed its methodological-analytical application. 
Within the emerging field of critical policy studies - which focuses on the making, mobilisation, and implementation of policy using critical social theory — assemblage thinking has been applied with particular enthusiasm and used primarily as a methodological-analytical framework (cf. Allen and Cohrane 2007; Prince 2010; McCann and Ward 2012; Wood 2015). As such it offers a way of revealing, interpreting, and representing the spatially, socially, and materially diverse worlds of policy and policy-making. For example, Prince (2010: 173) claims that an "implemented policy is an assemblage of texts, actors, agencies, institutions, and networks". He goes on to note that while policies form and are embedded in particular locations they are "constituted by a complex of relations, including the increasingly spatially stretched relations constitutive of globalisation". In studies of policy mobility, a subset of critical policy research, assemblage thinking has become a valuable methodological tool, frequently used to disaggregate the phalanx of actors, materials, processes, and practices that help mobilise particular policy ideas (cf. McCann et al. 2013; Pow 2014; Prince 2014). Rather than revel in empirical specificity for its own sake, the methodological strategy favoured by policy mobility researchers suggests that an engagement with difference and particularity can inform theory testing and development. To date, this has been practiced primarily through the framework of political economy, often in combination with insights from post-structural and post-colonial scholarship. This work overlaps significantly with debates in urban studies, where the apparent porosity of the urban and its politics has caused conceptual and methodological approaches to be reconsidered ( $M^{\mathrm{c}}$ Guirk et al. 2016). Many have been drawn to assemblage thinking as a means to understand how cities become "politically meaningful spatial entities" (Allen and Cochrane 2007: 1163). Operating from relational but by no means identical ontologies, urban studies scholars-particularly those interested in governance and policy-have 
been attracted by synergies between the spatially and materially heterogeneous nature of the urban and the way assemblage thinking asks how spatially and materially heterogeneous entities, like cities and urban policies, cohere (cf. Farías and Bender 2010; Robinson 2016).

Given that assemblage thinking is so often methodological, its application demands an explicitly methodological discussion. Yet few have explicitly elaborated on the character of assemblage methodologies in a direct and holistic manner (though see Bueger 2014). Even sparser are assessments of the specific opportunities and challenges such methodologies present for the critical study of policy, a field that has taken up assemblage thinking with verve. Building on insights synthesised from the literature, as well as those gleaned from our own assemblageinspired research on Australian homelessness policy-making, here we aim to specify the character and implications of assemblage methodologies. To do this we suggest a suite of epistemological commitments associated with assemblage methodologies. We then move to more specific terrain by considering the opportunities and challenges involved in applying these commitments in critical policy studies. Drawing on the project described at the outset, we discuss how the combination of three practices_-adopting an ethnographic sensibility, tracing sites and situations, and revealing labours of assembling_-offers a means to operationalise assemblage methodologies in critical policy studies.

\section{Commitments}

Assemblage methodologies, like all methodologies, are guided by epistemological commitments that signify a certain interrogative orientation toward the world. Though abstract, these commitments inform inclusions, priorities, and sensitivities, which together constitute the field of 
vision brought to bear on empirical phenomena. Sifting through the substantial number of accounts using assemblage thinking, we can identify four commitments common to those using assemblage methodologically. These are commitments to revealing multiplicity, processuality, labour, and uncertainty.

First, assemblage methodologies demand that research phenomena be approached as the "product of multiple determinations that are not reducible to a single logic" (Collier and Ong 2005: 12). In acknowledging that "neither assemblages nor their various components necessarily display internal coherence" ( $\mathrm{M}^{\mathrm{c}}$ Guirk and Dowling 2009: 180), assemblage thinking's commitment to an assumption of multiplicity supplants recourse to claims of singular lines of determination in any given situation. In the context of governmental interventions, this offers a way to unpack the ensemble of interacting, sometimes contradictory, projects, actors, and materials that cohere in 'policy' (Li 2007). This way of approaching policy, according to McCann (2011: 146), positions otherwise hegemonic systems and discourses "as contingent assemblages, constituted by a range of forces and interests that may not be as internally coherent and unassailable as they often seem". The ontological assumption of multiplicity_and, relatedly, of over-determination-highlights assemblage thinking's insistence on non-linearity and contingency, which can be downplayed or erased in orientations more prone to seeking the presence and power of the structural and the systemic (McFarlane and Anderson 2011). In other words, the determinants of policy outcomes in any given situation are not linear, cannot be predetermined, and are an empirical question, resolved contingently in specific contexts, as assemblages of heterogeneous actants cohere, and the properties and capacities of these actants are variously mobilised (see $\mathrm{M}^{\mathrm{c}} \mathrm{Guirk}$ et al. 2016) 
The assumption of multiplicity does not seek to deny the effect of power asymmetries that differentially position certain actors, knowledges, and places. Rather it aims to situate structures in the diverse and dynamic contexts in which they take shape and give shape, necessitating empirically rich accounts able to reveal how structural effects are realised through a congested field of projects, actors, and ambitions. MGuirk and Dowling's (2009: 177) account of an ostensibly neoliberal governance arena, private residential estates, shows how an assumption of multiplicity revealed "the practical co-existence of multiple political projects, modes of governance, practices and outcomes" that, for the most part, had gone unnoticed in accounts quick to assert the salience of neoliberal determinants. Through an assemblage reading, their account provides a means to understand actually existing neoliberalisation, using McFarlane's (2011b: 379) words, "not as a singular, circulating encompassing hegemonic force, but as a contingent set of translating logics that have to be enacted in practice". In assemblage methodologies, multiplicity is thus an interpretative strategy used to displace presumptions of structural coherence and determination. Recent works such as Fast Policy (Peck and Theodore 2015) and Give a Man a Fish (Ferguson 2015) -both major contributions to critical policy scholarship_practice an assumption of multiplicity as a means to understand the polyvalent, adaptive, and politically alloyed quality of policy-making and implementation. Whether the ultimate explanatory goal is understanding the neoliberal moment or its nascent 'others', an assumption of multiplicity remains an invaluable analytical manoeuvre for critical policy scholars, and it is one that assemblage methodologies put front and centre. 
Second, assemblage methodologies are committed to processuality. Indeed, part of the way assemblage thinkers act on the assumption of multiplicity is by collapsing structure and agency into a concern with process (Tonkiss 2011: 584). As Wise (2005: 77, original emphasis) claims, assemblage "is a concept dealing with the play of contingency and structure, organization and change ... the process of arranging, organizing, fitting together" of disparate actors, objects, techniques, organisations, representations, and so forth. What happens in process-during the arranging, organising and fitting together-is therefore central to the phenomena under investigation. For Ong (2007: 5), who sees assemblage as concerning how "promiscuous entanglements crystallize different conditions of possibility", it is through process that the effect of an assemblage is established. Underscoring the promiscuity of assemblages, Anderson and McFarlane (2011: 126) stress that the processes constituting assemblages are only ever provisional: "relations may change, new elements may enter, alliances may be broken, new conjunctions may be fostered. Assemblages are constantly opening up to new lines of flight, new becomings". Although attention to process is partly about resisting the notion of stability to insist, instead, on a view of the world as emergent and in flux (see Legg 2009: 238), assemblage methodologies also emphasise provisional stabilisation, disassembly, and reassembly. Their concern with process incorporates sensitivity to both stability and change. In methodological terms, a focus on the processes through which assemblages come into and out of being lends itself to careful genealogical tracing of how past alignments and associations have informed the present and how contemporary conditions and actants are crystallising new conditions of possibility. Policy scholars have gone to some effort highlighting the importance of processes, ranging from transnational institutional shifts to embodied learning (Peck and Theodore 2015; McFarlane 2011c). Although accounts differ in their prioritisation of certain processes over others, there is broad agreement that policy decisions, models, and knowledges are overdetermined by a 
conflagration of interactive processes and practices. In assemblage thinking, these conflagrations demand empirical investigation into the ways that processes and practices come together to render their (never pre-determined) effects.

Third, assemblage methodologies are committed to revealing the labours that produce and maintain assemblages: the labours of assembling. This commitment echoes Delueze and Guattari's original term agencement_roughly meaning 'putting together' or 'arrangement' — later translated to assemblage (Wise 2005). Assemblages are not accidental, but knowingly and unknowingly held together. For McCann (2011: 145, original emphasis), “assemblages are always coming apart as much as coming together, so their existence in particular configurations is something that must be continually worked at'. Studying 'creative industries' policy-making, Prince (2010: 169) emphasises the significant political and technical work involved in its emergence in New Zealand. Using an assemblage approach, he reveals how "different kinds of work, including the alignment of divergent political motivations, the translation of different ideas, and the invention of new concepts and programmes", were necessary to incorporate the creative industries into the policy apparatus. By this way of thinking, policy requires labour: the continued effort of human actors and the enrolment and often unforeseen effects of various materials and techniques through activities that range from everyday toil to executive decree. Assemblage methodology explicitly attends to these efforts, enrolments, and effects-these labours of assembling_-to reveal policy and policy-making as a laboured-over achievement.

From the perspective of assemblage methodologies, it is important to stress that labour does not operate in isolation. The agency residing in labour is not held by or within individuals. It is instead 
distributed relationally across an assemblage, raising questions about the location and causality of agency (Anderson and McFarlane 2011: 125). To understand the way actors operate, assemblage methodologies insist that we analyse how those actors are advantaged or disadvantaged by particular contexts and how they marshal resources, expertise, relationships, and the like to enable action. This, in turn, demands taking the role of materials and non-human beings seriously as critical elements in the distribution of agency (Robbins and Marks 2010). Despite different perspectives on the agential status of the other-than-human (cf. Tonkiss 2011; Farías and Bender 2010), there is wide acceptance of the need not only to unpack how agency is distributed across humans, but how human agencies are intertwined and enabled by a host of materials essential to labours of assembling. Processes of policy-making and implementation are no less saturated with intermediating materials than other domains of life. Consultant reports, briefs, meeting minutes, presentation slides, and spreadsheets are all part of the jumble through which human intentionality is projected. Returning to creative industries policy, Prince (2010) highlights the importance of technical knowledge (e.g. concepts and calculations) and its material presence in circulating documents to account for the spread of creative industries policy in numerous countries. Material (e.g. documents) and ideational elements (e.g. decontextualised concepts and data) were essential to enabling the creative industries to become a thinkable and actionable policy concept for a variety of actors to advance their goals and agendas. By grasping the constitutive roles played by non-human elements in the labours that constitute policy, assemblage methodologies decentre individualist conceptions of labour and direct attention to the way agential capacities are distributed across dynamic formations of humans and materials. 
Finally, while assemblage methodologies foreground multiplicity, processuality, and labour, they are also committed to an auto-critical disposition. This is in large part about maintaining a sense of uncertainty_eschewing the temptation to "know too much" (Gibson-Graham 2008: 619)— and seeking to avoid the imposition of rigid explanatory frameworks in favour of an uncertain and flexible approach. McCann and Ward (2012: 43) claim that assemblage "encourages and rewards a methodological openness and flexibility", and grapples with the "reality of unexpected connections, mutations, and research sites emerging during [research] projects". Likewise, Anderson and McFarlane (2011: 126) argue that assemblage thinkers should favour an approach that "opens the researcher up to risk, embraces uncertainty, expresses something of the fragility of composition". An emphasis on uncertainty is consistent with calls from critical policy scholars, particularly in urban-centric debates, for less determinative and more experimental analytical stances, stressing provisionality (O’Callaghan 2012), revisability (Robinson 2013), and modesty (Cochrane and Ward 2012). In line with post-positivist work generally, assemblage methodologies reflect an insistence on the situated nature of knowing and knowledge production (Le Heron and Lewis 2011). Such a position involves accepting that, rather than producing Archimedean accounts of the world 'as it is', social research can only produce situated readings and, therefore, must make modest claims. Accordingly, recent accounts have emphasised the need to enlarge the application of assemblage thinking from the realm of research phenomena 'out there' to see the research process as an act of assembling (Greenhough 2012), subject to the same contingencies, fragilities, and distributed agencies as that being researched (McCann and Ward 2012; McFarlane and Anderson 2011). In the context of critical policy studies, McCann and Ward (2012: 49) point out that research does not simply 'report' through analysis and writing, rather "our writing of the policy world ... is, in itself, an assemblage". From project inception, participant recruitment, and data analysis through to publication, dissemination, and citation, research accounts are 
fundamentally shaped by decisions arising from the practicalities of identifying and accessing key human and non-human actors and sites, the influence of theoretical and disciplinary traditions, and the style of interpretation, explanation, and representation used. Assemblage methodologies, like those closely related with actor-network theory, acknowledge that researchers are not distanced observers of reality but embedded translators with a "powerful position in the translation of the research environment in question" (Ruming 2009: 455). As we discuss in the following section, this commitment to uncertainty-along with multiplicity, processuality, and labour-has particular resonance for critical policy scholarship, and brings with it particular opportunities and challenges.

\section{Practices for the study of policy-making}

After specifying the epistemological commitments reflected across assemblage methodologies, we now turn toward more grounded terrain. We move from discussing abstract commitments to the task of operationalising those commitments for the study of policy-making. This requires the specification of methodological practices. Of course, given that assemblage methodologies can be applied to diverse empirical phenomena, these practices will necessarily require further tailoring to align them with the nature of the empirical case under investigation ${ }^{2}$. In light of the interest critical policy scholars have shown in assemblage methodologies, we focus on the specific opportunities and challenges facing studies of policy-making. We propose three practices that help operationalise the commitments of assemblage methodologies for such studies: (i) adopting an ethnographic sensibility, (ii) tracing sites and situations, and (iii) revealing labours of assembling.

2 For example, Swanton's (2013) study of the steel industry would have entailed a different set of specific methodological practices had it been a study focusing on the making of industry policy-making, even if both share the epistemological commitments typical of assemblage thinking. 


\section{Adopting an ethnographic sensibility}

Assemblage's epistemological commitments require a methodological orientation that delivers indepth qualitative understanding (to make multiplicity, process, and labour visible) of situated contexts (to enact uncertainty). Ethnographic styles of research directly address this requirement. Indeed, there is increasing interest in policy ethnographies that seek to penetrate the assumptive and material worlds of policy actors and the policy process more broadly. Ethnographies of the policy process have a considerable history (Pollitt et al. 1990), and are recognised as overcoming the limitations of quantitative methodologies in accessing "the world of meanings, choices and resultant behaviours" (174). More recent work on policy mobilities sees ethnographic methodologies as well equipped to access both the technologies of government and the embodied knowledges that constitute policy (Peck and Theodore 2010; McCann and Ward 2012). And Mountz (2003: 633) promotes ethnography as a way of coming to grips with how "governmental policies and procedures unfold ... recursively, amid social and cultural contexts". In their own way, these works collectively recognise both the multiple components that are contingently drawn together in the contextual assemblage of policy and the usefulness of ethnographic methods for revealing these.

Yet ethnographic methods in policy research have pragmatic limitations. Traditional or idealtypical ethnographic research aspires to 'immersion' in research subjects' social and spatial context, and does so through prolonged interaction between researchers and research subjects. Analyses draw heavily on methods of participant observation, which seek to uncover "discrepancies between thoughts and deeds" (Herbert 2000: 551). While this is not beyond the 
scope of critical policy studies (see, for example, Mountz 2011), it presents challenges. In our study on Housing First policy-making in Australia, labyrinthine institutional structures, hard-toidentify policy actors, and systems of organisational consent meant that prolonged engagement within key policy actors' professional environments were replaced by semi-structured interviews. Moreover, in the resource-scarce and competitive funding environment of social policy-a very real part of the context of Housing First-bureaucracies are often risk averse when it comes to

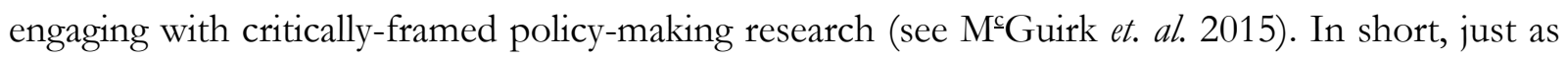
Kuus (2013: 18) notes in her research on foreign policy bureaucracies, policy-making settings around Housing First were not places where we as researchers could "chummily hang around". Immersion in the daily work of policy actors was not an option.

Acknowledging the challenges of traditional ethnography, our assemblage methodology was nonetheless informed by an ethnographic sensibility in which we took pragmatic cues from ethnographic approaches in order to operationalise the commitments of assemblage thinking. For policy anthropologists Shore and Wright (2011: 15), ethnography is not limited to a prescribed set of methods. It is also a 'sensibility', a “critical and questioning disposition that treats the familiar as strange". Roy's (2012) invocation of 'defamiliarisation' as part of on ethnographic sensibility highlights the potential for enacting the epistemological commitments of assemblage. She sees defamiliarisation — a move that need not be limited to participant observation or other immersive methods-as an inductive strategy that grapples with the situated articulation of multiple interacting processes and labours that produce socio-spatial phenomena such as policy. Interviewing and documentary analysis, both indispensable methods for policy researchers, provide opportunities for constituting detailed and defamiliarised accounts of practice. In interviews with policy actors, interviewees can be invited to step beyond seamless narratives of 
intention, unsettling the "technical and ideological parameters" (Kuus 2013: 4) and presuppositions of their field as they become_at least temporarily_reflexive 'double agents' (Roy 2012). For the researcher, this means treating interviews as occasions to actively probe the contingent socio-material alignments and taken-for-granted labours of the policy-making process. For documentary analysis, an ethnographic sensibility also encourages the researcher to treat documentary materials, such as reports and downloadable PowerPoint presentation slides, as ethnographic artefacts that provide windows into the creation, mobilisation, and application of policy knowledge. These artefacts function, on the one hand, as texts that reveal particular ways of thinking and acting, and on the other, as lively objects whose itineraries and effects can be apprehended by following their 'traces' in different contexts.

With our research on Housing First, an ethnographic sensibility attuned to defamiliarisation allowed us to develop a detailed and situated account of policy and policy-making that foregrounded the multiple determinations, interactive processes, and diverse labours at work in assembling policy, as well as their relational configuration across a diversity of sites (see Desmond 2014). Three examples are illustrative. First, we deployed an ethnographic sensibility in interviews to defamiliarise the seemingly apolitical and technical framings-associated with program evaluation science and administrative cost studies—that pervaded Housing First policy-making. We used interview questions, for instance, to explore the relational and often multiscalar processes whereby the technical knowledge and expertise embedded in these evaluations and studies were drawn together to constitute target populations (i.e. the chronically homeless) and align those populations with appropriate solutions (i.e. Housing First). Defamiliarisation also made visible the multiple crosscutting agendas and arguments at work in efforts to 'count and 
cost' the homeless, some framed by narrow fiscal logic and others by the compassionate logic of 'counting what you care about'.

Second, we used interviews to reveal how specific documentary materials, far from being incidental, were thoroughly implicated in popularising Housing First as a policy fix. In one interview, a social service manager involved in advocating for Common Ground projects reflected on the use of before-and-after photographs of formerly homeless clients who had been accommodated in a Housing First facility. The photographs were sourced from colleagues in the United States and used in meetings with Australian decision-makers to argue for the effectiveness and worth of Housing First approaches by eliciting an affective response that 'dry' statistics could not induce. Having interviewees reflect on documentary artefacts allowed us too to understand the many types of labour-on the part of policy actors, program clients, and the transformational before-and-after photos themselves-involved in constructing Housing First's status as a proven 'solution'. This status was, in turn, central to Housing First's rapid and widespread adoption in Australia.

Finally, the stories of policy-making gathered in our interviews allowed us to capture the uncertainty in policy-making pathways, rendering strange the assumption that these pathways are determinable by abstract rationalities, such as neoliberalism. Our interviews revealed a host of seemingly mundane, unforeseeable events that were consequential in how the Common Ground model was assembled in Australia. For example, a social service manager reflected on her initial meeting with Common Ground's founder Rosanne Haggerty. After a spur-of-the-moment encounter over coffee, the service manager came away filled with admiration for Haggerty's achievements and excitement over the possibility of approaching homelessness differently. 
Contingent on that initial impromptu meeting, and facilitated through Haggerty's professional networks, in the months that followed the service manager travelled to New York and other cities in the United States, visiting Housing First facilities and meeting staff. The social service manager went on to be an influential figure in establishing the Sydney Common Ground project and in the national conversation on Housing First.

\section{Tracing sites and situations}

Assemblage thinking's epistemological commitments to multiple determination, interactive processes, and labour dispel any notion that 'policy' is simply made in particular bureaucratic sites and projected across neat jurisdictional space. Rather, they suggest that policy-making emerges through the relational and interactive configuration of actors, events, materials, and projects which display complex, relational spatialities. Thus, the spatial constitution of a policy assemblage is multiple, processually realised, and continually in the making. In line with a commitment to uncertainty, assemblage methodologies require the 'reach' and intensity of methodological attention not be predetermined. These viewpoints chime with recent thinking in critical policy research which, in a number of ways, has grappled with the implications of similarly relational, socially constructed, and less presumptive understandings of space in studies of policy (Bulkeley 2005; Allen and Cochrane 2007; Legg 2009; McCann and Ward 2010; Baker and Ruming 2015; Peck and Theodore 2015). Prince's (2015) assemblage-inspired account, for example, demonstrates how policy is embroiled in the unfolding actions of policy actors and the circulation of various materials across multiple spatialities. For him, "a 'policy world' does not have a predefined geographical constitution: its geography depends on what and where the policy touches in order to cohere recognisably as policy" (5). Beyond those using the rubric of assemblage, scholars of policy and governance have been cautious of the use of blunt, pre- 
determined spatialities that tend to reify and presume the primacy of the nation-state via 'methodological nationalism' (Stone 2004). Within the literature on urban policy and governance, some have critiqued an analogous susceptibility to 'methodological city-ism' (Angelo and Wachsmuth 2015), accompanied by calls for research that grasps the spatial complexity of urban governance through more grounded and inductive research practices, and more revisable and provisional categories (for context, see Peck 2014; Robinson 2016).

These perspectives have much in common with assemblage's epistemological commitments. Yet, their burden quickly becomes methodological. Whereas traditional policy research tends to begin with a set of assumptions about jurisdictional authority and the roles of certain policy actors, instruments, and institutions in a given situation, in assemblage-inflected studies the spatiality of methodological foci is situated and neither self-evident nor singular. To dispense with the notion of pre-scaled methodological foci, and in line with assemblage's wider commitments, we suggest the iterative and inductive methodological practice of tracing 'sites and situations' (McCann and Ward 2012). Here, we draw from anthropologists, who have made sustained and longstanding calls for "a radical reconceptualization of 'the field' [that policy researchers investigate] ... not as a discrete local community or bounded geographical area, but as a social and political space articulated through relations" (Shore and Wright 1997: 14; see also Wedel et al. 2005). Similarly, geographers have increasingly reconfigured their methodological foci, away from static and spatially-tethered notions of policy-making towards its understanding as an unruly assemblage of territorialised and relational elements (McCann and Ward 2010; Barber 2013). We align with McCann and Ward (2012) who find that attending to the sites and situations implicated in the making of policy offers a way to escape the methodological-analytical constraints of the bounded 
research field and explore the active and unpredictable composition of policy ${ }^{3}$. They advocate an approach that inductively and iteratively traces people, discourses, and policy ideas to particular localised sites and examines their embedding in wider social and spatial situations. Sites, in this sense, might include a conference hall, a social service facility, the offices of a ministry, or the administrative territory of a city, while situations might relate to prevailing notions of best practice or a hegemonic political-ideological project that exists beyond, but is nonetheless constituted by, particular sites. Drawing on assemblage thinking, their framing of the 'field' or the 'study area' as a series of interrelated sites and situations ${ }^{4}$ whose interrelation is traced over the course of a research project corresponds with "the composite and relational character of policies ... [and] the various social practices that gather, or draw together, diverse elements of the world into relatively stable and coherent 'things'" (McCann and Ward 2012: 43). Aligning with the commitment to uncertainly associated with assemblage thinking, they add that such an approach "encourages and rewards a methodological openness and flexibility" (43).

In our study of Housing First policy-making in Australia, the methodological practices of tracing sites and situations meant resisting the impulse, common in policy research, to rely on static jurisdictional territories to frame our analysis. We made no assumption that the 'Australian experience' could be framed as what occurs within the nested territorial hierarchy of the Australian state, with prescribed relations between the local, regional, and national scales or clear, observable distinctions between what lies within and beyond those scales. Rather we allowed for these relations and their spatialities to emerge empirically. As is increasingly acknowledged, these

\footnotetext{
3 This stance has strong affinities with the notion of relational ethnography (Desmond 2014) which is consistent with assemblage thinking in its emphasis on the constitution of any object of study not by coherent pre-configured bounded groups or sites/places but rather by configurations of networks of relations. This turn aligns with Burawoy's (1998) extended case method and its inherently topological, territorially unbounded approach.

${ }^{4}$ In Desmond's (2014) terms, these constitute the 'ecology of the field'.
} 
neat territorial demarcations provide little purchase for critical analyses of policy-making. Rather, we began by focusing on the seven Common Ground facilities that were under construction, or being planned, at the beginning of the research. Through these sites $^{5}$, which were located in five different states and six local government areas, we built an understanding of additional sites that were involved in debates, learning activities, and decisions related to the Common Ground model and Housing First approaches, and the various situations those sites were shaped by and were themselves shaping. Sites included: institutions such as bureaucracies, social service organisations, consultancy firms, and advocacy organisations; places such as Canberra, Adelaide, New York City, and London; and events such as study tours, meetings, and public lectures. By piecing together this spatially dispersed yet relationally proximate causal collection of sites, we began to reveal the multiply determined, processually aligned and actively composed dynamics of the Housing First policy-making in Australia. This enabled us to identify and recognise empirically the relations between various sites, their socio-material constitution, and their situation in congested political, institutional, and professional fields. In this way, the sites just listed were analysed as arenas through which diverse, 'wider' projects of fiscal conservativism, technocratic rationality, and social progressivism were translated, and their alignments and tensions worked through (see Baker and Evans 2015). The methodological practice of following the sites and situations associated with the emergence of Housing First ideas in Australia allowed us to operationalise assemblage thinking's commitment to policy-making as over-determined, processually realised and produced through a diverse array of actors and materials.

\section{Revealing labours of assembling}

\footnotetext{
${ }^{5}$ Understood as simultaneously territorial and topologically constituted.
} 
Assemblage thinking's epistemological commitments foreground the socio-material labours of assembling policy. These labours are multiple, incorporating a wide range of policy actors and materials situated in different spatial contexts and configurations. They are processual, in the sense that policy is laboured-over, through the work of cohering, repairing, and disassembling, and have unpredictable effects, given the shifting nature of policy assemblages. So far, we have advocated an ethnographic sensibility that defamiliarises the worlds of policy, and suggested an approach to the policy-making research field based around tracing sites and situations. These two practices are complemented, and maximised, by paying close attention to the grounded work of assembling policy. More precisely: if an ethnographic sensibility is concerned with 'how to look', and tracing sites and situations is concerned with 'where to look', a methodological practice directed to the task of revealing labours of assembling is concerned with 'what to look for'.

While critical policy research has historically downplayed policy work in favour of disembodied analyses of institutional and regulatory-level change, there is a growing realisation of the need to take the labours of policy-making seriously. Policy researchers have tended to think of policy as an abstraction (Freeman 2011), over-looking the multiple forms of work that bring it into being. This has begun to change, with recent accounts focusing on topics such as the institutionally and professionally embedded production of policy documents (Freeman and Maybin 2011), the socially and politically complex performance of expertise (Kuus 2014), and the ways in which protocols, technologies, and legal prescriptions frame policy actors' understandings of, and responses to, certain populations (Feldman 2011). In an effort to further understand the labours of policy-making, a growing number of studies examine the way policy ideas are learned. Using assemblage thinking, McFarlane (2011c) offers an understanding of policy learning as a social, geographical, and material process that prompts a shift in perception. Building on this account, 
Rapoport (2015), for example, examines the role of 'photoshopped' images of urban redevelopment in constituting the way policy actors learn about and, in a more affective register, 'inhabit' current and future policy scenarios. These accounts have been accompanied with studies of learning through 'policy tourism', wherein policy actors visit foreign places and sites to selfconsciously learn from their experiences (see González 2009; Cook and Ward 2011; Wood 2014).

For assemblage methodologies, these studies align with the notions that policy is an assemblage and that policy-making involves the labour required to cohere heterogeneous elementscharismatic individuals, professional norms and experiences, institutionalised procedures, material bodies of evidence and documentation, and ideological and electoral circumstance. This perspective led us to analyse the relational and distributed labours that configured Housing First. In assessing claims that Common Ground was a 'successful' approach to chronic homelessness, we were drawn to analyse the conditions that make such claims possible as well as the conditions that make it compelling to various audiences. This led us to position claims of policy success in relation to circulating narratives of policy failure, compelling evidence in the form of tables and graphs, ongoing engagements with recognised experts such as Rosanne Haggerty, the formation of new policy objects such as the chronically homeless population, and sites of Housing First practice and evidence generation in Australia and the United States. All of these factors bear down on the claim of Common Ground being a successful policy approach and demonstrate how material and discursive labours of assembling lie behind this conjuring of the policy, its power, and effects.

Aside from aligning with assemblage thinking's commitments to process and labour, staying close to the work of policy is crucial for actualising commitments to uncertainty and multiplicity. By 
remaining close to the ground, where pristine policy visions and political rhetoric meet the day-today routines, encounters, and materialities of policy-making, attention is directed to the ways in which hegemonic projects and forces—such as neoliberalism, developmentalism, etc-are processually resisted, undermined, negotiated, and consolidated in diverse socio-spatial contexts. For instance, Larner and Laurie (2010) document the manner in which neoliberal privatisation agendas were translated, questioned, and hybridised through the geographically varied knowledges and experiences of everyday policy actors, in their case, a cast of 'middling technocrats'. Similarly, Le Heron (2009) attends to the social atmospheres of micro-spaces such as the meeting room, where norms are reproduced and rendered vulnerable, and where the potential exists for unexpected but decisive turns. Indeed, by paying attention to the grounded work of Housing First policy-making, we uncovered a diverse range of projects and agendas that helped account for why, how, and in what manner that particular idea could be reassembled in Australia. This ranged from structural under-resourcing of the homeless services system, to Prime Minister Rudd's personal drive to elevate homelessness nationally, to well-meaning efforts to make the homeless service system more 'effective', to canny actions of service providers and advocates who chose their political moment to launch an alternative to the debilitating treatment-treadmill that many homeless persons with severe illnesses face. Staying empirically close to the labour of a wide range of policy actors thus provided access into the uncertain and politically-alloyed negotiations of the policy world.

\section{Conclusion}

Despite the popularity of assemblage thinking in critical policy studies, particularly as a methodological-analytical framework, there has been little explicit discussion about how to apply assemblage thinking methodologically. This paper has interrogated the essential task of aligning 
the abstract epistemological commitments of assemblage thinking with grounded methodological practices for policy research. Our account has stressed that operationalising assemblage thinking for methodological ends is not a straight-forward affair, nor something that conforms to a onesize-fits-all template. Accounting for the multiple, processual, and laboured production of the socio-material world through situated accounts demands a carefully considered set of methodological practices. For scholars of policy and policy-making, there are distinctive challenges which we sought to overcome through the adoption of a pragmatic ethnographic sensibility attuned to the barriers typical of policy-making environments, a focus on inductively tracing distanciated policy-making sites and their situations, and revealing the complex labours of assembling policy. These methodological practices are, nonetheless, experimental in at least two respects. First their foundation in a commitment to uncertainly prefigures the empirical investigation they enact as an experiment in understanding who, where, and what matters, as well as how they matter. Relatedly, they are experimental insofar as their engagement requires an open and exploratory ethos, infused with a willingness to follow empirical, sometimes unexpected, leads. They require, as Peck and Theodore (2015) recently put it, a willingness to 'go with the flow'. Furthermore, they lend themselves to forms of research presentation infused by storying (Cameron 2012) wherein the empirical-its characters, personalities, objects, coincidences, and contingencies_- has an insistent presence, unable to be comprehensively reduced or abstracted.

With assemblage thinking, the need to formulate appropriate methodological practices goes well beyond concerns related to doing methodologically 'sound' research. Such practices are crucial for successfully converting what are otherwise inert epistemological commitments into analyticalpolitical capacities (Carolan 2013; $M^{\mathrm{c}}$ Guirk et al. 2016). Assemblage methodologies provide a means to see, write, and enact the world of policy-making-enact in the sense that social scientific 
inquiry is generative (Le Heron and Lewis 2011) - in a way that reveals the (de/re)stabilisation of orders, institutions, networks, and terrains. Assemblage methodologies can support accounts that address the 'how' questions of policy practice, acting as both a complement and counterweight to accounts that focus on the effectiveness of institutional and structural processes. As $M^{\underline{c}}$ Guirk (2015: 6) points out, a focus on the way practices produce, sustain, and render effective certain processes is "important both to understanding how power conjures its effects and, likewise, how it might be made indeterminate or vulnerable". Without attending to the fine-grain of practice, critical policy scholars risk over-estimating the salience of influential actors and political projects, and under-estimating the contingencies, failures, course corrections, and re-directions that animate the making and implementation of policy. Whether exposing the fragile renewal of dominant agendas and political projects, or identifying and publicising latent alternatives, assemblage methodologies offer a promising way to enlarge the analytical-political capacities of critical policy scholarship.

\section{Acknowledgements}

We thank audience members at the Canadian Association of Geographers annual conference in Vancouver for their helpful feedback. Tom Baker wishes to thank Eugene McCann and Cristina Temenos for ongoing dialogue on critical policy studies and assemblage thinking.

\section{References}

Allen, J., and Cochrane, A. (2007). Beyond the territorial fix: Regional assemblages, politics and power. Regional Studies, 41(9), 1161-1175.

Anderson, B. and McFarlane, C. (2011). Assemblage and geography. Area, 43(2), 124-127. 
Angelo, H. and Wachsmuth, D. (2015). Urbanizing urban political ecology: A critique of methodological cityism. International Journal of Urban and Regional Research, 39(1), 16-27.

Baker, T. and Evans, J. (2016). 'Housing first' and the changing terrains of homeless governance. Geography Compass, 10(1), 25-41.

Baker, T. and Ruming, K. (2015). Making “Global Sydney”: Spatial imaginaries, worlding and strategic plans. International Journal of Urban and Regional Research, 39(1), 62-78.

Barber, L. (2013). (Re)making heritage policy in Hong Kong: A relational politics of global knowledge and local innovation. Urban Studies, 51(6), 1179-1195.

Bibby, P. and Murray, E. (2009). Big Apple plan for Sydney homeless. Sydney Morning Herald, 3 August.

Brenner, N., Madden, D. J. and Wachsmuth, D. (2011). Assemblage urbanism and the challenges of critical urban theory. City, 15(2), 225-240.

Bueger, C. (2014). Thinking assemblages methodologically: Some rules of thumb. In Acuto, M. and Curtis, S. (eds.), Reassembling international theory: Assemblage thinking and international relations. Basingstoke: Palgrave Macmillan.

Bulkeley, H. (2005). Reconfiguring environmental governance: Towards a politics of scales and networks. Political Geography, 24(8), 875-902.

Burawoy, M. (1998). The extended case method. Sociological Theory, 16(1), 4-33.

Cameron, E. (2012). New geographies of story and storytelling. Progress in Human Geography, 36(5), $573-592$.

Carolan, M. (2013). Doing and enacting economies of value: Thinking through the assemblage. New Zealand Geographer, 69(3), 176-179.

Clarke, J., Bainton, D., Lendvai, N. and Stubbs, P. (2015). Making policy move: Towards a politics of translation and assemblage. Bristol: The Policy Press. 
Cochrane, A. and Ward, K. (2012). Researching the geographies of policy mobility: Confronting the methodological challenges. Environment and Planning A, 44(1), 5-12.

Collier, S. J. and Ong, A. (2005). Global assemblages, anthropological problems. In Collier, S. J. and Ong, A. (eds.), Global assemblages: Technology, politics, and ethics as anthropological problems. Malden, Mass.: Blackwell.

Cook, I. R. and Ward, K. (2011). Trans-urban networks of learning, mega events and policy tourism: The case of Manchester's Commonwealth and Olympic Games projects. Urban Studies, 48(12), 2519-2535.

Desmond, M. (2014). Relational ethnography. Theory and Society, 43(5), 547-579.

Farías, I. and Bender, T. (eds.). (2010). Urban assemblages: how Actor-Network Theory changes urban studies. London: Routledge.

Feldman, G. (2011). The migration apparatus: Security, labor, and policymaking in the European Union. Palo Alto: Stanford University Press.

Ferguson, J. (2015). Give a man a fish: Reflections on the new politics of distribution. Durham: Duke University Press.

Freeman, R. (2011). The practice of policy making. Evidence \& Policy, 7(2), 127-136.

Freeman, R. and Maybin, J. (2011). Documents, practices and policy. Evidence \& Policy, 7(2), 155170.

Gibson-Graham, J. K. (2008). Diverse economies: Performative practices for "other worlds." Progress in Human Geography, 32(5), 613-632.

González, S. (2011). Bilbao and Barcelona "in motion". How urban regeneration "models" travel and mutate in the global flows of policy tourism. Urban Studies, 48, 1397-1418.

Greenhough, B. (2012). On the agencement of the academic geographer. Dialogues in Human Geography, 2(2), 202-206. 
Grove, K. and Pugh, J. (2015). Assemblage thinking and participatory development: Potentiality, ethics, biopolitics. Geography Compass, 9(1), 1-13.

Herbert, S. (2000). For ethnography. Progress in Human Geography, 24, 550-568.

Kuus, M. (2013). Foreign policy and ethnography: A sceptical intervention. Geopolitics, 18(1), 115131.

Kuus, M. (2014). Geopolitics and expertise: Knowledge and authority in European diplomacy. Malden, Mass.: John Wiley and Sons.

Larner, W. and Laurie, N. (2010). Travelling technocrats, embodied knowledges: Globalising privatisation in telecoms and water. Geoforum, 41(2), 218-226.

Legg, S. (2009). Of scales, networks and assemblages: The League of Nations apparatus and the scalar sovereignty of the Government of India. Transactions of the Institute of British Geographers, 34(2), 234-253.

Le Heron, R. (2009). "Rooms and moments" in neoliberalising policy trajectories of metropolitan Auckland, New Zealand: Towards constituting progressive spaces through post-structural political economy. Asia Pacific Viewpoint, 50(2), 135-153.

Le Heron, R. and Lewis, N. (2011). New value from asking 'Is geography what geographers do?'. Geoforum, 42(1), 1-5.

Li, T. M. (2007). Practices of assemblage and community forest management. Economy and Society, 36(2), 263-293.

McCann, E. (2011). Veritable inventions: Cities, policies and assemblage. Area, 43(2), 143-147.

McCann, E., Roy, A. and Ward, K. (2013). Assembling/Worlding Cities. Urban Geography, 34(5), $581-589$.

McCann, E. and Ward, K. (2010). Relationality/territoriality: Toward a conceptualization of cities in the world. Geoforum, 41(2), 175-184. 
McCann, E. and Ward, K. (2012). Assembling urbanism: Following policies and "studying through" the sites and situations of policy making. Environment and Planning A, 44(1), 42-51.

McFarlane, C. (2009). Translocal assemblages: Space, power and social movements. Geoforum, 40, $561-567$.

McFarlane, C. (2011a). Assemblage and critical urbanism. City, 15(2), 204-224.

McFarlane, C. (2011b). On context. City, 15(3-4), 375-388.

McFarlane, C. (2011c). Learning the city: Knowledge and translocal assemblage. Malden, Mass.: WileyBlackwell.

McFarlane, C. and Anderson, B. (2011). Thinking with assemblage. Area, 43(2), 162-164.

MGuirk, P. (2015). Practicing fast policy at and beyond the edges of neoliberalism. Political Geography. In press.

Mㄷuirk, P. and Dowling, R. (2009). Neoliberal privatisation? Remapping the public and the private in Sydney's masterplanned residential estates. Political Geography, 28(3), 174-185.

Mㄷuirk, P., O’Neill, P.M. and Mee, K. J. (2015). Effective practices for interagency data sharing: Insights from collaborative research in a regional intervention, Australian Journal of Public Administration, 74, 199-211.

$\mathrm{M}^{\mathrm{c}} \mathrm{Guirk}, \mathrm{P}$., Mee K, J. and Ruming, K. (2016). Assembling urban regeneration? Resourcing critical generative accounts of urban regeneration through assemblage. Geography Compass. In press.

Mountz, A. (2003). Human smuggling, the transnational imaginary, and everyday geographies of the nation-state. Antipode, 35(3), 622-644.

Mountz, A. (2011). Seeking asylum: Human smuggling and bureaucracy at the border. Minneapolis: University of Minnesota Press. 
Müller, M. (2015) Assemblages and actor-networks: Rethinking socio-material power, politics and space. Geography Compass, 9(1), 27-41.

O’Callaghan, C. (2012). Contrapuntal urbanisms: Towards a postcolonial relational geography. Environment and Planning A, 44(8), 1930-1950.

Ong, A. (2007). Neoliberalism as a mobile technology. Transactions of the Institute of British Geographers, 32(1), 3-8.

Peck, J. (2014). Cities beyond compare? Regional Studies, 49(1), 160-182.

Peck, J., and Theodore, N. (2010). Mobilizing policy: Models, methods, and mutations. Geoforum, 41(2), 169-174.

Peck, J. and Theodore, N. (2015). Fast policy: Experimental statecraft at the thresholds of neoliberalism. Minneapolis: University of Minnesota Press.

Pollitt, C., Harrison, S., Hunter, D. J. and Marnoch, G. (1990). No hiding place: On the discomforts of researching the contemporary policy process. Journal of Social Policy, 19(2), 169-190.

Pow, C. P. (2014). License to travel: Policy assemblage and the "Singapore model." City, 18(3), 287-306.

Prince, R. (2010). Policy transfer as policy assemblage: Making policy for the creative industries in New Zealand. Environment and Planning A, 42(1), 169-186.

Prince, R. (2014). Consultants and the global assemblage of culture and creativity. Transactions of the Institute of British Geographers, 39(1), 90-101.

Prince, R. (2015). The spaces in between: Mobile policy and the topographies and topologies of the technocracy. Environment and Planning D: Society and Space. In press.

Rankin, K. N. (2011). Assemblage and the politics of thick description. City, 15(5), 563-569. 
Rapoport, E. (2015). Sustainable urbanism in the age of Photoshop: Images, experiences and the role of learning through inhabiting the international travels of a planning model. Global Networks, 15(3), 307-324.

Robbins, P., and Marks, B. (2010). Assemblage geographies. In Smith, S. J., Pain, R., Marston, S. and Jones, J. P. (eds.), The SAGE Handbook of Social Geographies. Los Angeles: Sage.

Robinson, J. (2013). The travels of urban neoliberalism: Taking stock of the internationalization of urban theory. Urban Geography, 32(8), 1087-1109.

Robinson, J. (2015). 'Arriving at' urban policies: The topological spaces of urban policy mobility. International Journal of Urban and Regional Research, 39(4), 831-834.

Robinson, J. (2016). Thinking cities through elsewhere: Comparative tactics for a more global urban studies. Progress in Human Geography, 40(1), 3-29.

Roy, A. (2012). Ethnographic circulations: Space-time relations in the worlds of poverty management. Environment and Planning A, 44(1), 31-41.

Ruming, K. (2009). Following the actors: Mobilising an actor-network theory methodology in geography. Australian Geographer, 40(4), 451-469.

Shore, C. and Wright, S. (1997). Policy: A new field of anthropology. In Shore, C. and Wright, S. (eds.), Anthropology of public policy: Critical perspectives on governance and power. London: Routledge.

Shore, C. and Wright, S. (2011). Conceptualising policy: Technologies of governance and the politics of visibility. In Shore, C., Wright, S. and Pero, D. (eds.), Policy worlds: Anthropology and the analysis of contemporary power. New York: Berghahn Books.

Stone, D. (2004). Transfer agents and global networks in the "transnationalization" of policy. Journal of European Public Policy, 11(3), 545-566.

Swanton, D. (2013). The steel plant as assemblage. Geoforum, 44, 282-291.

Tonkiss, F. (2011). Template urbanism: Four points about assemblage. City, 15(5), 584-588. 
Wedel, J. R., Shore, C., Feldman, G. and Lathrop, S. (2005). Toward an anthropology of public policy. The Annals of the American Academy of Political and Social Science, 600(1), 30-51.

Wood, A. (2014). Learning through policy tourism: Circulating bus rapid transit from South America to South Africa. Environment and Planning A, 46, 2654-2669.

Wood, A. (2015). Tracing policy movements: Methods for studying learning and policy circulation. Environment and Planning $A$. In press.

Wise, J. M. (2005). Assemblage. In Stivale, C. (ed.), Gilles Deleure: Key concepts. Montreal: McGillQueen's University Press. 